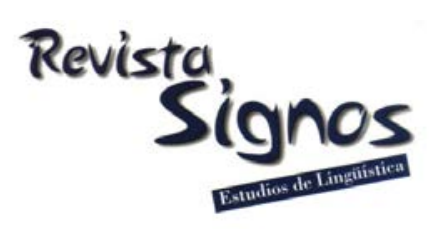

\title{
The effect of learning English as a foreign language on the temporal and spatial perception of Persian learners
}

\section{El efecto del aprendizaje del inglés como lengua extranjera en la percepción temporal y espacial de los educandos persas}

\author{
Meisam Rahimi \\ UNIVERSITY OF ISFAHAN \\ IRAN \\ rahimi.meysam@gmail.com
}

\author{
Mansoor Tavakoli \\ UNIVERSITY OF ISFAHAN \\ mr.tavakoli14@gmail.com
}

Recibido: 06-XI-2015 / Aceptado: 13-VI-2016

\begin{abstract}
The findings of the current research on language and thought provide supporting evidence for the idea that language can have a profound effect on thought. In two studies, the authors examined the effect of learning English as a foreign language on the temporal and spatial perception of Persian learners. In the first study, 99 participants and in the second study 92 participants were recruited. The participants were assigned to three groups of monolinguals, low level bilinguals and high level bilinguals based on their performance on the Oxford Quick Placement Test (QPT). Drawing on the assumptions of Construal Level Theory (CLT, Trope \& Liberman, 2003), we primed global processing in participants through Navon's task (1977). Having completed the task, participants were required to estimate temporal and spatial distances in a number of situations. The results of the studies suggest that learning a foreign language can have an impact on the temporal and spatial cognition of language learners.
\end{abstract}

Key Words: Level of construal, construal level theory, psychological distance, bilingualism, linguistic relativity. 


\section{Resumen}

Los resultados de esta investigación sobre el lenguaje y el pensamiento proporcionan evidencia que apoya la idea de que el lenguaje puede tener un efecto profundo en el pensamiento. En dos estudios, los autores examinaron el efecto del aprendizaje del inglés como lengua extranjera en la percepción temporal y espacial de un grupo de alumnos persas. 99 participantes fueron reclutados en el primer estudio y 92 participantes en el segundo estudio. Los participantes fueron asignados a tres grupos de monolingües, bilingües de nivel bajo y alto nivel bilingüe a partir de su desempeño en la Oxford Quick Placement Test (QPT). Basándose en los supuestos de la teoría del nivel de construal (CLT, Trope \& Liberman, 2003), elicitamos un procesamiento global en los participantes a través de la tarea de Navon (1977). Una vez completada la tarea, se exigió a los participantes estimar las distancias temporales y espaciales en una serie de situaciones. Los resultados de estos estudios sugieren que el aprendizaje de una lengua extranjera puede tener un impacto en la cognición espacial y temporal de los estudiantes del idioma.

Palabras Clave: Nivel de construal, teoría del nivel de construal, distancia psicológica, bilingüismo, aprendizaje de idiomas.

\section{INTRODUCTION}

The idea that language affects the way we realize the reality and the world around us has long attracted the attention of scholar from different fields. The issue attracted more attention with the introduction of the Linguistic Relativity Hypothesis. While research findings have provided evidence against the strong version of the hypothesis, proposing that the speakers of a language think in a way imposed by the language they speak, a growing body of evidence (Lucy, 1992; Levinson, 1996; Roberson, 2005) has been provided which support the weak version, proposing that a language can have built-in unavoidable mechanisms which would prime specific cognitive patterns or construals (Jarvis, 2007; Carroll, 2008).

Generally speaking, construal refers to an individual's subjective interpretation or understanding of a phenomenon (VandenBos, 2015). High-level construals are considered to be relatively abstract mental representations which retain the central features of a phenomenon and remove the features that are incidental and idiosyncratic. For example, by representing a 'cellular phone' as 'a communication device', we retain the information about the function of the object and omit the information about size. Furthermore, high-level construals tend to be more schematic, more coherent, more prototypical, and less ambiguous than low-level construals.

According to Construal Level Theory (CLT), psychological distance refers to transcending the direct experience of the self, here, and now through abstraction. CLT proposes that level of construal can affect and be affected by the distance on the four dimensions of time, space, social distance, and hypotheticality (CLT), Liberman and Trope (2008); Liberman, Trope and Stephan (2007); Trope and Liberman (2003). In 
other words, a phenomenon would be represented on an increasingly higher level of construal as the phenomenon becomes more psychologically distant, and more abstract construals would lead to perceiving more psychological distances. Specifically speaking, it is proposed that people form more abstract mental construals as they consider something in more distant remote locations (spatial distance) and in the more distant future and past (temporal distances), in regard to socially distant others (social distance), and in hypothetical situations (hypotheticality).

The present paper follows up on the assumptions of CLT to examine the impact of learning English as a foreign language on the psychological distance of the learners in the spatial and temporal domains. Specifically, the study tries to examine whether learning English as a foreign language would cause Persian EFL learners to perceive spatial and temporal distances in significantly different ways.

\section{Language-thought interfaces}

Recent research on the interaction between language and thought has yielded a more complicated picture than the distinction made between linguistic relativity and linguistic determinism. Figure 1 presents an overview of the subtle and intriguing interactions between language and thought.

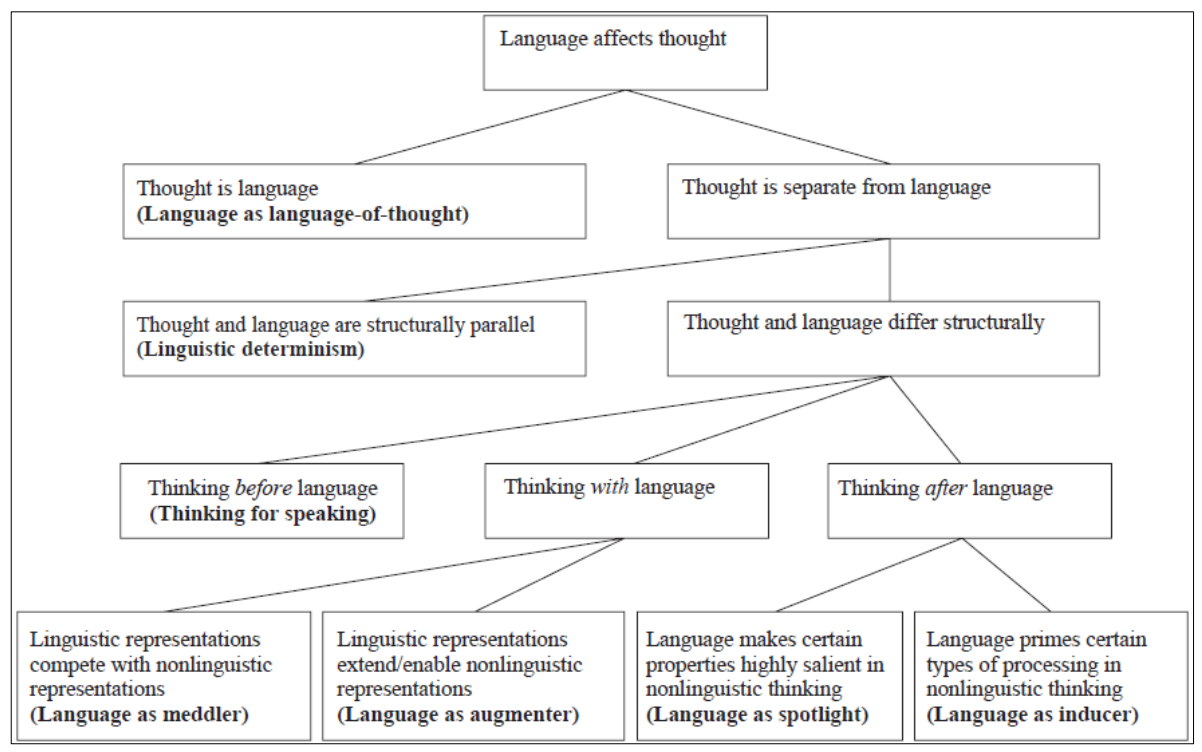

Figure 1. The hypotheses on the possible interactions between language and thought Source: Wolff and Holmes (2011).

The first class of the hypotheses proposes that natural language lexical units are used as the building blocks of thoughts. Research findings have indicated that this class of language-thought interaction is not tenable. For example, research has showed that infants and nonhuman primates are able to form relatively elaborate 
thoughts in the absence of language (Penn, Holyoak \& Povinelli, 2008). The second class, proposing that language and thought are two separate entities, is divided into two subclasses. As the first subclass, linguistic determinism postulates that any language has its own conceptual categories and perceptual processes and that learning a new language would overwrite the pre-existing categories and processes. Findings of the related research indicate that there is no such alignment between language and thought. For example, Papafragou, Massey and Gleitman (2006) experimentally compared children's and adults' motion descriptions in Greek and English. Their findings indicated that the speakers' surface linguistic encoding did not shape their mental representation of events.

On the other hand, three sets of language-thought interfaces have been identified which support the idea that language and thought are not structurally parallel. First, research has demonstrated that thought processes immediately prior to language use might be influenced by language. For example, Papafragou, Hulbert and Trueswell (2008) compared eye movement of Greek and English speakers as they watched motion events. When the participants were required to prepare verbal descriptions, their eyes focused on the aspects of the events which were typically encoded in their native language. However, when they freely watched the ongoing events, their eyemovement patterns did not differ significantly.

Another subclass of non-parallelism between language and thought postulated that both non-linguistic and linguistic processes are activated simultaneously. In one class of this research, linguistic code acts as a meddler which is either consistent with nonlinguistic code, facilitating speed and accuracy, or inconsistent with the non-linguistic code, decreasing speed and accuracy. The results of a study by Gilbert, Regier, Kay and Ivry (2006) indicated that participants' reaction times to the target presented in the right visual field were faster when the names of the target and the distractor colours differed, but their reaction times were not affected when the target was presented in the left visual field. It was argued that the observed effect might be due to the fact that the stimulus presented in the right visual field is initially processed in the left hemisphere which is usually associated with language processing. It has also been proposed that linguistic code might act as an augmenter, in the sense that linguistic and non-linguistic representations are used in combination to improve performance. Frank, Everett, Fedorenko and Gibson (2008) showed that members of the Pirahã, an Amazonian tribe, lacked a linguistic code for expressing exact quantity. In fact, they used the word hói to refer to quantities up to six items, hoi to refer to 4-10 items, and baágiso to refer to 7 to 10 items. Gordon (2004) investigated whether lacking words to encode larger numbers would have any effect on Pirahã speakers' performance while manipulating exact quantities. In a matching task, the speakers were presented an array of objects and were required to respond by providing a corresponding array of batteries. The results of the study indicated that the speakers 
failed to provide the exact number of batteries required, perhaps due to the numerical gap in the Pirahã language.

Research findings have also indicated that language can impact thought even after it has been used. It is posited that the acquisition of a language might generate a specific processing mode, which might persist in both linguistic and non-linguistic contexts. A subclass of this view proposes that acquiring a language would cause speakers to pay greater attention to some specific properties of the physical context. For example, three kinds of spatial frames of reference have been identified: the geocentric or absolute frame which places the coordination axes in the larger environment, the object-centric or intrinsic frame which consider the axes within objects, and the ego-centric frame which considers the speaker as the point of reference (Majid, Bowerman, Kita, Haun \& Levinson, 2004). It has been observed that not all frames of reference are used in all languages. In a series of experiments, Levinson, Kita, Haun and Rasch (2002) found a correlation between linguistically encoded frames of reference and the performance of the speakers in non-linguistic tasks. They argued that the correlation could be attributed to the influence of language on the selection of special frames in non-linguistic tasks. It has also been indicated that language might act as an inducer that would prime particular processing modes that would persist even in non-linguistic contexts. For example, Holmes and Wolff (2010) investigated the representation of schematic forms (schematic language and depictions) in the brain. The results of their study revealed an association between simulated motions and participates' relatively schematic conceptualization of the motions. Accounting for the association, they argued that language may promote using schematic representations and induce abstraction.

\section{L2 Language-construal interface}

Researchers within the domains of bilingualism and second language acquisition have recently made attempts to investigate systematically the language-thought interfaces in second language (L2) speakers in a variety of perceptual domains such as categorization, number, grammatical gender, time, and colour (Jarvis, 2011; Jarvis \& Pavlenko, 2008). Research has indicated that learning new languages can lead to the acquisition of new categorization systems (Cook, Bassetti, Kasai, Sasaki \& Takahashi, 2006; Athanasopoulos, 2007). For instance, it has been shown that speakers of Japanese, a language in which nouns are mass-like, tend to categorize items based on their material or substance, while speakers of English, a language in which number is grammatically marked and count nouns are distinguished from mass nouns, usually prefer to categorize objects based on their shape (Imai \& Gentner, 1997). Using an object classification task, Athanasopoulos (2007) investigated the categorization preferences of Japanese L2 learners of English. The results of the study indicated that Japanese-English bilinguals shifted their categorization preferences towards the L2 
pattern as a result of the acquisition of the second language. The observed behaviour was attributed to the count-mass grammatical conceptualizations in the two languages. In another study, Cook et al. (2006) found that while English monolinguals tended to categorize items based on their shape and Japanese monolinguals tended to categorize items based on their substance, Japanese-English bilinguals used both systems for categorizing items, providing further evidence for the claim that learning a language can have an impact on the cognitive processing of language learners beyond language.

Some studies have documented the effect of language on construal in the domains of number and grammatical gender. The acquisition of grammatical gender has been shown to have an influence on the learners' perception of objects (Forbes, PoulinDubois, Rivero \& Sera, 2008). For example, the results of a study by Kurinski and Sera (2011) showed that as English L2 learners of Spanish acquired grammatical gender, their categorization tendencies also changed. Specifically, participants were more disposed to attributing male/female voices based on the Spanish grammatical gender system, even when they used English to do the tasks. The effect of learning a second language on the number cognition of learners has also been observed. For instance, Athanasopoulos (2006) compared English monolinguals with Japanese L2 learners of English. Athanasopoulos (2006) found that while intermediate Japanese L2 learners of English behaved like Japanese monolinguals in that they tended to notice the increases in both countable and uncountable items, advanced Japanese L2 learners of English acted more like English monolinguals in that they were more likely to notice increase in countable items. Athanasopoulos (2006) argued that these findings support the idea that acquiring a second language can alter L1 cognitive tendencies.

Research has also provided supporting evidence of cognitive shift in bilinguals in time and colour domains. In the domain of time, for instance, it has been shown that while in English horizontal metaphors are usually used to show the flow of time, in Mandarin vertical metaphors are employed to express temporal succession (Boroditsky, 2001). The results of the study by Miles, Tan, Noble, Lumsden and Macrae (2011) showed that Mandarin-English bilinguals employed both horizontal and vertical time lines in contexts where linguistic content was minimized. In colour domain, a number of studies have suggested that acquiring a second language might lead to changes in colour perception along the colour spectrum. For example, taking the fact that Greek distinguishes a darker shade of blue called ble and a lighter shade of blue called ghalazio, Athanasopoulos (2009) investigated the colour categorization of Greek L2 learners of English. Results of the study indicated that the bilinguals' distinction between light and dark blue shades weakened as their level of bilingualism increased (see also Athanasopoulos, Dering, Wiggett, Kuipers \& Thierry, 2010). In a similar study, Athanasopoulos, Damjanovic, Krajciova and Sasaki (2011) investigated Japanese-English bilinguals' sensitivity to the light blue/blue distinction, which 
showed that the bilinguals who used Japanese more frequently distinguished light blue and blue better than those who used English more frequently.

The interaction between language and construal has also been confirmed in studies on motion domain. A number of studies have been conducted based on the idea that the speakers of languages with aspectual marking (English, Spanish) have a tendency not to mention the endpoint or goal of an event, whereas the speakers of the languages where aspectual marking is absent (German, Swedish) have a reverse tendency (Athanasopoulos \& Bylund, 2013). Bylund, Athanasopoulos and Oostendorp (2013) tested the hypothesis by measuring motion endpoint behaviour of the speakers of Afrikaans (a non-aspect language) through a non-linguistic similarity judgment task and a linguistic retelling task. They compared the behaviour of the Afrikaans speakers with that of the Swedish speakers (another non-aspect language) and English speakers (an aspect marking language). Results indicated that the Afrikaans speakers' encoding patterns approximated Swedish patterns, but significantly diverged from the English patterns.

\section{Construal Level Theory}

Much research within the framework of CLT has demonstrated the association between construal level and psychological distance (Liberman \& Trope, 2008, 2014; Trope \& Liberman, 2010). The evidence has been provided at the level of both explicit judgments and implicit associations. For example, the association between psychological distance and construal level has been examined using an Implicit Association Test (Bar-Anan, Liberman \& Trope, 2006). Participants were presented with four stimuli categories: stimuli relating to high-level construal, stimuli relating to low-level construal, stimuli relating to low psychological distance, and stimuli relating to high psychological distance. In congruent trials, distant stimuli were paired with high-level stimuli and proximal stimuli were paired with low-level stimuli, whereas on incongruent trials, proximal stimuli were paired with high-level stimuli and distal stimuli were paired with low-level stimuli. The participants showed higher reaction time with incongruent pairs than congruent pairs on all four dimensions of psychological distance, indicating the implicit association participants made between high-level construal and psychological distance, and low-level construal and psychological proximity.

Within the domain of visual perception, similar findings have been provided. For example, Liberman and Förster (2009) first primed participants with temporal proximity or temporal distance by asking them to write about their lives tomorrow or a day a year later and then presented Navon's (1977) task. In comparison to a control group whose participants did not write about their lives, temporal proximity facilitated processing of local letters and impaired processing of global letters, whereas temporal distance had the opposite effect. Similar effects were observed for spatial and social 
distance priming. To examine the influence of global-local perception on psychological distance, Liberman and Förster (2009) first used a variation of Navon's (1977) task to prime participants with either local or global processing. In comparison with the control condition, the participants in the global processing condition estimated greater spatial distance, social distance, temporal distance, and hypotheticality, whereas the participants in the local processing condition behaved reversely.

Assuming that pictures comprise low-level construals, whereas words represent high-level construals (Amit, Algom, Trope \& Liberman, 2008; Amit, Algom \& Trope, 2009) Amit et al. (2009) found that participants arranged items into more groups as pictures were used to present items than when words were used to present them. In another study, either pictures or words were used to present temporally, spatially, or socially distant or near items. Participants were required to quickly identify the objects. The results indicated that spatial proximity facilitated object identification when the items were presented in the pictorial format, and spatial distance facilitated object identification when the items were presented in the verbal format. Considering other psychological distance dimensions, similar results were obtained when psychologically proximal objects were represented by pictures and psychologically distal objects were presented by words.

Assuming that distant entities are construed more abstractly, individuals should classify items into broader categories if the items are considered in distant situations than in proximal situations. Research has supported the prediction by showing that people classify objects into broader, fewer categories when the objects are considered in distant future situations than near future situations (Liberman, Sagristano \& Trope, 2002, Study 1) or in unlikely situations than likely situations (Wakslak, Trope, Liberman \& Alony, 2006). In line with the research on categorization, research on event segmentation has shown that individuals divide ongoing events into broader segments when the behaviour is psychologically distal than proximal. For example, Henderson, Fujita, Trope and Liberman (2006) asked participants at the New York University to partition an animated film of three supposed teenagers at a well-known camp into as many sections as they considered appropriate. In the proximal condition, the camp was considered to be on the East Coast and in the distal condition it was considered to be on the West Coast. Participants made broader, fewer sections when they imagined the teenagers in the spatially distant location than the spatially near location. Furthermore, a series of studies by Wakslak and Trope (2009) indicated that manipulating categorization level in different ways had a significant impact on event likelihood estimations. Specifically, participants who were primed to high-level construals through manipulating categorization level indicated that the events were less likely to happen than the participants who were primed to low-level construals. 
Actions, like objects, can be identified (construed) in different ways and arranged in a cognitive hierarchy, from low-level identities (construals in concrete terms) which specify the way an action is performed to high-level identities (construals in abstract terms) which specify the reason for which an action is performed or the effects of an action. Research has indicated that more distant future activities are described in highlevel terms rather than low-level terms (Liberman \& Trope, 1998). Similar effects have been observed when actions were imagined in spatially distant locations (Fujita, Henderson, Eng, Trope \& Liberman, 2006), when the actions were considered unlikely to occur (Wakslak et al., 2006), and when the perceiver and the actor were considered to be dissimilar (Liviatan, Trope \& Liberman, 2008). The effect of level of construal on the estimation of psychological distance has also been supported by research findings. Research has indicated that when people think about an activity in high-level terms than in low-level terms, they imagine more temporally distant activities (Liberman, Trope, Macrae \& Sherman, 2007; McCrae, Liberman, Trope \& Sherman, 2008) and people more socially distant (Stephan, Liberman \& Trope, 2010).

\section{The present studies}

Considering the assumptions of the CLT and the evidence on the effect of second language acquisition on the construal of learners, in two studies, we examined the effect of learning English as a foreign language on temporal (Study 1) and spatial (Study 2) psychological distances of Persian learners. In fact, we sought evidence for the idea that second language acquisition can lead to cognitive restructuring in the bilingual mind.

Two methods have been frequently used to measure language proficiency: selfreports (e.g. Bylund \& Athanasopoulos, 2014) and formal tests (e.g. Bylund \& Jarvis, 2011). Scholars have questioned self-report surveys as valid and reliable measures of language proficiency (e.g. Dörnyei, 2001) mainly due to the subjectivity inherent in self-reports, as participants may over or under report their ability. Another criticism against self-reports is participants' insufficient experience in self-assessment. Considering the criticism leveled at self-report, in the present study, Oxford Quick Placement Test (QPT; Oxford University Press, 2001) was used to divide participants into the three groups.

\section{Study 1: Temporal distance}

In this study, participants were first primed with global processing. Then, they imagined that they were invited for a free examination in a dental clinic in their neighbourhood and estimated how long from now they would go for the examination. 


\subsection{Method}

\subsubsection{Participants}

Ninety-nine individuals were recruited for the study for a number of allegedly unrelated psychological tests. The participants were divided into three groups based on their performance on the Oxford Quick Placement Test (QPT): monolinguals ${ }^{1}$ (13 females, 20 males; $\left.M_{\text {age }}=23.60 ; S D_{\text {age }}=4.47\right)$, low-level bilinguals ${ }^{2}(15$ females, 18 males; $\left.M_{\text {age }}=32.12 ; S D_{\text {age }}=5.95\right)$, and high-level bilinguals ${ }^{3}$ (12 females, 21 males; $M_{\text {age }}=28.93 ; S D_{\text {age }}=5.96$ ). Participants had only been exposed to English in secondary and post-secondary education and in language institutes.

\subsubsection{Procedure}

Data collections were run individually. All participants gave informed consent. Participants were primed to think more abstractly using the global-local reaction time task (Förster \& Higgins, 2005; Förster, Liberman \& Kuschel, 2008; Liberman \& Förster, 2009). In this computerized task, a number of composite letters (see Figure 2) were used.

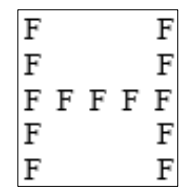

Figure 2. Each composite letter was made of an approximately $2.5 \mathrm{~cm} \times 2.5 \mathrm{~cm}$ global letter and a number of approximately $0.5 \mathrm{~cm} \times 0.5 \mathrm{~cm}$ local letters. Each vertical or horizontal line of the global letter was made of five local letters.

First, a cross $(+)$ was shown in the centre of the screen for 500 ms. Then, a composite letter was presented, and participants were required to press a blue key as quickly as possible if the presented stimulus contained the letter $L$ and a red key if the presented stimulus contained the letter $H$. The task was set up so that the participants always had to respond to global letters. More specifically, the four presented composite letters always included global target letters (an $L$ made of $F$ s, and an $L$ made of $T \mathrm{~s}$, an $H$ made of $T \mathrm{~s}$, an $H$ made of $F \mathrm{~s}$ ) and no local target letters. Next, participants were required to complete a judgment task. Specifically, participants were required to imagine that a new dental clinic had opened in their neighbourhood and that they received an invitation for a free dental examination and cleaning. They were asked how many days from then they would go. To control some potential covariates, participants were required to state when they last visited a dentist, whether they were afraid of visiting dentists, and whether they liked going to a dentist. The data for these factors were not used for further analysis because they did not correlate with the dependent measure. None of the participants considered the tasks related in any way. 


\subsection{Results}

The descriptive statistics of the data are presented in Table 1.

Table 1. Mean estimates of the temporal distance.

\begin{tabular}{|l|c|c|c|}
\hline & Monolingual & $\begin{array}{c}\text { Low-Level } \\
\text { Bilingual }\end{array}$ & $\begin{array}{c}\text { High-level } \\
\text { Bilingual }\end{array}$ \\
\hline Mean & 11.36 & 10.36 & 6.72 \\
\hline Std. Deviation & 2.77 & 2.01 & 2.95 \\
\hline
\end{tabular}

To evaluate the significance of the difference between the means of the groups, a one-way analysis of variance (ANOVA) was conducted. The result of the ANOVA revealed a significant difference between the means, $\mathrm{F}(2,96)=28.845, \mathrm{p}<0.001$. A Post-hoc comparison of the means, using Tukey test, was also applied to determine the precise locations of significant differences. The results of the analysis indicated that the mean score of high-level bilinguals was significantly different from both monolinguals and low-level bilinguals. However, the performance of monolinguals did not significantly differ from the performance of low-level bilinguals. The obtained effect size value $(r=0.581)$ was large according to Cohen's thresholds for interpreting effect size.

The results of the study show that compared to monolinguals and low-level bilinguals, high-level bilinguals perceived the future event as significantly less distant. Considering the relation between the construal level and psychological distance, the lower estimation of the temporal distance by high-level bilinguals can be attributed to their lower level of construal.

\section{Study 2: Spatial distance}

In this study, participants were primed with global processing and then they were required to estimate three spatial distances (Henderson et al., 2006). In Study 2A and 2B participants estimated spatial distance from some specific geographical locations, whereas in Study 2C they estimated spatial distance from a specific point within the experimental room.

\subsection{Method}

\subsubsection{Participants}

Ninety-two individuals were recruited for the study for a number of allegedly unrelated psychological tests. The participants were divided into three groups based on their performance on the Oxford Quick Placement Test (QPT): monolinguals ${ }^{1}$ (17 females, 13 males; $M_{\text {age }}=28.93 ; S D_{\text {age }}=7.34$ ), low-level bilinguals ${ }^{2}(14$ females, 18 males; $M_{\text {age }}=29.81 ; S D_{\text {age }}=7.18$ ), and high-level bilinguals ${ }^{3}$ (14 females, 16 males; $\left.M_{\text {age }}=30.3 ; S D_{\text {age }}=6.15\right)$. Participants had only been exposed to English in secondary and post-secondary education and in language institutes. 


\subsubsection{Procedure}

Data collections were run individually. All participants gave informed consent. Like Study 1, participants were primed to think more abstractly using the global procedure. Next, participants were required to complete a judgment task. In Study 2A, participants estimated how far away they were from Maydān-e Emām. In Study 2B, participants estimated the distance between Isfahan and Hamadān. In this study, participants also responded whether they were from Hamadān, whether they actually knew the distances, and whether they regularly commuted to Maydān-e Emām. The participants' answers to these questions were negative and, thus, the data were not used for further analysis. In Study 2C, participants estimated the distance between themselves and a marked point on a wall. The distance between the observer and the target point was about $170 \mathrm{~cm}$. None of the participants considered the tasks related in any way.

\subsection{Results}

Table 2 presents the descriptive statistics of the data.

Table 2. Mean estimates of the spatial distances.

\begin{tabular}{|l|c|c|c|c|c|c|}
\hline & \multicolumn{2}{|c|}{ Study 2A } & \multicolumn{2}{c|}{ Study 2B } & \multicolumn{2}{c|}{ Study 2C } \\
\hline & $M$ & $S D$ & $M$ & $S D$ & $M$ & $S D$ \\
\hline Monolingual & 10.63 & 2.39 & 548.33 & 52.13 & 168.00 & 21.23 \\
\hline Low-Level Bilingual & 10.78 & 1.69 & 519.37 & 22.85 & 165.31 & 20.63 \\
\hline High-level Bilingual & 5.70 & 2.10 & 474.00 & 62.67 & 121.66 & 22.90 \\
\hline
\end{tabular}

To evaluate the significance of the difference between the means of the groups, three ANOVAs were conducted. In Study $2 \mathrm{~A}$, the result of the ANOVA revealed a significant difference between the means, $F(2,89)=58.72, \mathrm{p}<0.001$. A Post-hoc comparison of the means, using Tukey test, was also applied to determine the precise locations of significant differences. The results of the analysis indicated that the mean score of high-level bilinguals was significantly different from both monolinguals and low-level bilinguals. However, the performance of monolinguals did not significantly differ from the performance of low-level bilinguals. The obtained effect size value ( $\mathrm{r}=$ 0.639) was large according to Cohen's thresholds for interpreting effect size.

The analysis of the assessment of the distance between Isfahan and Hamadān replicated the results of Study $2 \mathrm{~A}$. The ANOVA revealed a significant difference between the distance estimation of the participants in the three groups, $\mathrm{F}(2,89)=$ 17.95, $\mathrm{p}<0.001$. The results of the post-hoc analysis, using Tukey test, were also similar to Study 2A. the results indicated that while the performance of monolinguals and low-level bilinguals was not significantly different, there was a meaningful difference between the performance of high-level bilinguals and that of the other two groups. The obtained effect size value $(r=0.531)$ was large according to Cohen's thresholds for interpreting effect size. 
In Study 2C, the results of the ANOVA showed that the estimations of the distance to the point on the wall has been significantly different among the groups, $\mathrm{F}(2,89)=43.92, \mathrm{p}<0.001$. The results of the post-hoc analysis indicated that the participants in the high-level group perceived the distance significantly lower than the participants in the monolingual and low-level groups. However, the perception of the participants in monolingual and low-level groups did not differ significantly. The obtained effect size value $(r=0.624)$ was large according to Cohen's thresholds for interpreting effect size.

Overall, the results of the first study are replicated by Study 2. In the first study, lower estimations of temporal distance can be attributed to the relatively higher level of bilingualism. In a similar way, the higher level of bilingualism can be considered to be the factor which induced lower estimations of spatial distance by the high-level bilinguals. Besides, considering the relation between the construal level and psychological distance, perceiving lower spatial distances can be attributed to lower levels of construal. In other words, assuming that global processing induces greater psychological distances, it can be argued that higher-level participants estimated lower spatial distances because they construed events in relatively lower levels as a result of acquiring English.

\section{DISCUSSION}

In two studies, we examined the effect of learning English as a foreign language on spatial and temporal distance. Participants were primed to have high-level construal mindsets using the global-local reaction time task (Förster et al., 2008; Liberman \& Förster, 2009). Afterwards, they estimated a number of temporal and spatial distances. The results of the studies revealed that the participants with a higher level of bilingualism estimated significantly lower psychological distances. Considering the association between construal level and psychological distance in CLT (Trope \& Liberman, 2010; Liberman \& Trope, 2014), the observed effect can be attributed to the lower construal level of high-level bilinguals. More specifically, the present findings imply that learning a new language might influence the construal level of bilinguals, which in turn would affect their psychological distance. Considering the present study, learning English as a foreign language can be considered to be the factor which influenced the cognitive processing of the high-level learners so that they developed a marked tendency to construe different phenomena in a lower level, which in turn lead to significantly lower estimated temporal and spatial distance. The findings contribute to the growing body of research on the language-thought interaction in various perceptual domains (Elston-Guttler \& Williams, 2008; Kurinski \& Sera, 2011; Park \& Ziegler, 2014) by suggesting that learning a new language can have a significant impact on the cognitive behaviour of bilinguals. 
The relativistic effects of learning a new language can be attributed to crosslinguistic differences in grammatical or lexical systems (Bylund \& Athanasopoulos, 2014). In other words, languages differ in how they grammatically and/or lexically encode the reality. On the other hand, neuroscientific research has demonstrated that lexical and grammatical processing are interconnected and connected with other nonverbal cognitive processes (Kiefer \& Pulvermüller, 2012; Pulvermüller, 2003). There is a lack of research regrading grammatical or lexical discrepancies between Persian and English which yield to variations in conceptualization. However, while there does not seem to be any syntactic differences between the languages, such as the ones between English and Spanish (Filipović, 2011) and English and Japanese (Cook et al., 2006), which would lead to differences in construing events differently, the present results imply that there might be some crosslinguistic differences in how information is packed into lexical items in Persian and English. For example, it might be the case that there is a tendency in Persian to incorporate less semantic components in lexical units than English so that the lexical units would tend to represent more general conceptualizations or higher levels of construal. Assuming the interconnection between the verbal and nonverbal cognitive processing mentioned above, the higher levels of construal can be considered the source of variation in construing temporal and spatial distances across the two languages. Future studies on construal will certainly benefit from investigations into crosslinguistic differences in semantic representations between Persian and other languages and the extent to which these differences lead to crosslinguistic variations in construal across various domains.

Findings from the research on the language-thought interface suggest that the maintenance of language-specific cognitive processing of L2 learners is influenced by a number of factors such as frequency of language use (Park \& Ziegler, 2014), language proficiency (Athanasopoulos, 2007, 2009; Park \& Ziegler, 2014), age of acquisition onset (Bylund et al., 2013), and length of cultural immersion (Boroditsky, 2001; Cook et al., 2006; Athanasopoulos, 2007; Athanasopoulos et al., 2010; Bylund et al., 2013), language of instruction (Athanasopoulos, 2007). For example, Bylund et al. (2013) tested whether the speakers of Afrikaans (a non-aspect language) tended to encode event endpoints more than the Afrikaans L2 learners of English (an aspect language). Results of the study showed that the Afrikaans speakers' endpoint patterns was significantly different from English patterns. The results also indicated that the variation among the Afrikaans speakers could be partially accounted for by the speakers' frequency of use of English, in a way that endpoint behaviour of the bilinguals who used English more frequently was more similar to English speakers. In line with the findings on the effect of language proficiency on the cognitive restructuring in bilinguals, the results of the present study indicated that while monolinguals and low-level bilinguals estimated the distances similarly, high-level bilinguals estimated significantly lower distances. In other words, the present results 
imply that language proficiency can exert a significant influence on bilinguals' cognitive restructuring. Future studies can further clarify the impact of these variables usually associated with bilingualism on the construal level and psychological distance of bilinguals.

Of course, these findings do not necessarily imply that learning a particular language would impose specific cognitive behaviours. Li, Abarbanell, Gleitman and Papafragou (2011) conducted four experiments to see whether specific spatial frames of reference in language would prime corresponding spatial conceptualization, specifically in non-linguistic spatial tasks. The participants were members of a Mayan population whose language (Tseltal) uses geocentric spatial frames. The results of their study indicated that the participants at times used egocentric view in dealing with spatial tasks, indicating that spatial processing was not dictated by linguistic encoding.

The global-local processing distinction has proved to be important in cognitive and social psychology (Kühnen \& Oyserman, 2002; Förster \& Higgins, 2005). For example, research has indicated that global processing can be associated to such higher level processing as creative thought (Friedman, Fishbach, Förster,\& Werth, 2003), lower levels of anxiety (Mikulincer, Paz \& Kedem, 1990), and right hemispheric activation (Derryberry \& Tucker, 1994). Research has also shown that some of these variables are related to psychological distance. For example, research findings have indicated that temporal distance enhances creative thought (Förster et al., 2004) and focus on similarities (Förster et al., 2008). As another example, Levy, Freitas and Salovey (2002) found that individuals who construe actions abstractly are likely to consider themselves sharing goals with others and also perceive their own specific standards and goals as related to broader aims towards self-discipline, which in turn would lead to positive affect and maintaining motivational intensity. Given the findings regarding the effect of construal level on various cognitive and social phenomena, the results of this study suggest that learning a new language might play a role in these phenomena. For example, Freitas, Salovey and Liberman (2001) found that individuals who chronically used low-level construals had less interest in negative feedback and greater interest in downward social comparison (DSC). Assuming this, it might be the case that speakers of the languages with relatively lower action construal levels might show a greater interest in DSC and less interest in negative feedback. Considering the observed interaction between learning a second language, psychological distance, and construal level in the present study, perhaps that would be interesting to speculate about possible relations between bilingualism and such construal-mediated variables: Does bilingualism influence creative thinking, inasmuch as it is mediated by construal? Can learning a new language significantly lower the level of anxiety? Does learning a new language affect the learner's focus on similarities? 
Research has also suggested that there can be an interaction between perceptual and conceptual processing (Derryberry \& Tucker, 1994; Förster, Friedman, Ozelsel \& Denzler, 2006). For example, in a study by Friedman et al. (2003), participants completed visual tasks which made them focus their perceptual attention on a relatively narrow (local condition) or broad (global condition) visual area. Then, participants were required to generate the most unusual exemplars of certain categories. The results of the study indicated that the global condition, compared to the local condition, generated more unusual category exemplars. The effect of conceptual processing on perceptual processing was also demonstrated in a study by Stapel and Semin (2007). In this study, participants were primed to a high-level construal (using adjectives), versus a low-level construal (using concrete verbs). The results of the study indicated that the priming facilitated the perception of global gestalts rather than local details. Assuming the interaction between perceptual and conceptual processing and the findings of the present study, future studies can investigate the effect of bilingualism on one of the processing modes as the other one is considered as a covariate.

Considering the lack of research on the impact of language learning on construal level and psychological distance, additional research across other languages and groups of speakers and on other possible factors influencing the cognitive restructuring of bilinguals is needed to further clarify the observed effect.

\section{CONCLUSION}

The current study set out to investigate the relation between learning English as a foreign language and Persian EFL learners' construal level and psychological distance. The findings indicated that high-level bilinguals had developed a specific preference for estimating significantly lower psychological distances, compared to monolinguals and low-level bilinguals. Considering CLT, these findings can be attributed to the effect of language learning on the construal level of learners. The present findings have provided further evidence for the idea that language acquisition might have significant effects on thought so that language communities would develop biases toward specific processing modes, which reflects the ongoing perceptual restructuring that is occurring in the bilingual mind. Specifically speaking, the results of the present study have shown that acquiring a second language can exert a meaningful influence on language learners' psychological distance and construal level. It can be concluded that learning a new language can have significant effects on language learners' nonverbal cognitive processing. 


\section{REFERENCIAS BIBLIOGRÁFICAS}

Amit, E., Algom, D. \& Trope, Y. (2009). Distance-dependent processing of pictures and words. Journal of Experimental Psychology: General, 138, 400-415.

Amit, E., Algom, D., Trope, Y. \& Liberman, N. (2008). "Thou shalt not make unto thee any graven image": The distance-dependence of representation. In K. D. Markman, W. M. P. Klein \& J. A. Suhr (Eds.), The handbook of imagination and mental simulation (pp. 53-68). New York, NY: Psychology Press.

Athanasopoulos, P. (2006). Effects of the grammatical representation of number on cognition in bilinguals. Bilingualism, Language and Cognition, 9, 89-96.

Athanasopoulos, P. (2007). Interaction between grammatical categories and cognition in bilinguals: The role of proficiency, cultural immersion, and language of instruction. Language and Cognitive Processes, 22, 689- 699.

Athanasopoulos, P. (2009). Cognitive representation of colour in bilinguals: The case of Greek blues. Bilingualism: Language and Cognition, 12, 83-95.

Athanasopoulos, P. \& Bylund, E. (2013). Does grammatical aspect affect motion event cognition? A cross-linguistic comparison of English and Swedish speakers. Cognitive Science, 37, 286-309.

Athanasopoulos, P., Damjanovic, L., Krajciova, A. \& Sasaki, M. (2011). Representation of colour concepts in bilingual cognition: The case of Japanese blues. Bilingualism: Language and Cognition, 14, 9-17.

Athanasopoulos, P., Dering, B., Wiggett, A., Kuipers, J.-R. \& Thierry, G. (2010). Perceptual shift in bilingualism: Brain potentials reveal plasticity in preattentive colour perception. Cognition, 116, 437-443.

Bar-Anan, Y., Liberman, N. \& Trope, Y. (2006). The association between psychological distance and construal level: Evidence from an implicit association test. Journal of Experimental Psychology: General, 135, 609-622.

Boroditsky, L. (2001). Does language shape thought? Mandarin and English speakers' conceptions of time. Cognitive Psychology, 43, 1-22.

Bylund, E. \& Jarvis, S. (2011). L2 effects on L1 event conceptualization. Bilingualism: Language and Cognition, 14, 47-59.

Bylund, E. \& Athanasopoulos, P. (2014). Language and thought in a multilingual context: The case of isiXhosa. Bilingualism: Language and Cognition, 17(2), 431441. Doi: doi:10.1017/S1366728913000503. 
Bylund, E., Athanasopoulos, P. \& Oostendorp, M. (2013). Motion event cognition and grammatical aspect: Evidence from Afrikaans. Linguistics, 51, 929-955.

Carroll, D. W. (2008). Psychology of language (5th edn.). Belmont, CA: Thomson Wadsworth.

Cook, V., Bassetti, B., Kasai, C., Sasaki, M. \& Takahashi, J. (2006). Do bilinguals have different concepts? The case of shape and material in Japanese L2 users of English, International Journal of Bilingualism, 10(2), 137-52.

Derryberry, D. \& Tucker, D. M. (1994). Motivating the focus of attention. In P. M. Niedenthal \& S. Kitayama (Eds.), Heart's eye: Emotional influences in perception and attention (pp. 167-196). New York: Academic Press.

Dörnyei, Z. (2001). Teaching and researching motivation. Harlow: Longman.

Elston,-Guttler, K. E. \& Williams, J. N. (2008). First language polysemy affects second language meaning interpretation: Evidence for activation of first language concepts during second language reading. Second Language Research, 24(2), 167-87.

Filipović, L. (2011). Speaking and remembering in one or two languages: Bilingual vs. monolingual lexicalization and memory for motion events. International Journal of Bilingualism, 15(4), 466-485.

Forbes, J. N., Poulin-Dubois, D., Rivero, M. \& Sera, M. (2008). Grammatical gender affects bilinguals' conceptual gender: Implications for linguistic relativity and decision making. The Open Applied Linguistics Journal, 1, 68-76.

Förster, J. \& Higgins, E. T. (2005). How global versus local perception fits regulatory focus. Psychological Science, 16, 631-636.

Förster, J., Friedman, R. S. \& Liberman, N. (2004). Temporal construal effects on abstract and concrete thinking: Consequences for insight and creative cognition. Journal of Personality and Social Psychology, 87, 177-189.

Förster, J., Liberman, N. \& Kuschel, S. (2008). The effect of global versus local processing styles on assimilation versus contrast in social Judgment. Journal of Personality and Social Psychology, 94, 579-599.

Förster, J., Friedman, R. S., Özelsel, A. \& Denzler, M. (2006). Enactment of approach and avoidance behavior influences the scope of perceptual and conceptual attention. Journal of Experimental Social Psychology, 42(2), 133-146.

Frank, M. C., Everett, D. L., Fedorenko, E. \& Gibson, E. (2008). Number as a cognitive technology: Evidence from Pirahã language and cognition. Cognition, 108(3), 819-824. 
Freitas, A. L., Salovey, P. \& Liberman, N. (2001). Abstract and concrete selfevaluative goals. Journal of Personality and Social Psychology, 80, 410-424.

Friedman, R. S., Fishbach, A., Förster, J. \& Werth, L. (2003). Attentional priming effects on creativity. Creativity Research Journal, 15, 277-286.

Fujita, K., Henderson, M., Eng, J., Trope, Y. \& Liberman, N. (2006). Spatial distance and mental construal of social events. Psychological Science, 17, 278-282.

Gilbert, A. L., Regier, T., Kay, P. \& Ivry, R. B. (2006). Whorf hypothesis is supported in the right visual field but not the left. Proceedings of the National Academy of Sciences of the United States of America, 103(2), 489-494.

Gordon, P. (2004). Numerical cognition without words: Evidence from Amazonia. Science, 306(5695), 496-499.

Henderson, M. D., Fujita, K., Trope, Y. \& Liberman, N. (2006). Transcending the "here": The effect of spatial distance on social judgment. Journal of Personality and Social Psychology, 91, 845-856.

Holmes, K. J. \& Wolff, P. (2010). Simulation from schematics: Dorsal stream processing and the perception of implied motion. Proceedings of the 32nd Annual Conference of the Cognitive Science Society, Portland, Oregon, USA.

Imai, M. \& Gentner, D. (1997). A cross-linguistic study of early word meaning: Universal ontology and linguistic influence. Cognition, 62, 169-200.

Jarvis, S. (2007). Theoretical and methodological issues in the investigation of conceptual transfer. Vigo International Journal of Applied Linguistics, 4, 43-71.

Jarvis, S. (2011). Crosslinguistic influence in bilinguals' concepts and conceptualizations. Bilingualism: Language and Cognition, 14, 1-8.

Jarvis, S. \& Pavlenko, A. (2008). Crosslinguistic influence in language and cognition. New York: Routledge.

Kiefer, M. \& Pulvermüller, F. (2012). Conceptual representations in mind and brain: theoretical developments, current evidence and future directions. Cortex, $48(7), 805-825$.

Kühnen, U. \& Oyserman, D. (2002). Thinking about the self-influences thinking in general: Cognitive consequences of salient self-concept. Journal of Experimental Social Psychology, 38, 492-499.

Kurinski, E. \& Sera, M. D. (2011). Does learning Spanish grammatical gender change English-speaking adults' categorization of inanimate objects? Bilingualism: Language and Cognition, 14, 203-220. 
Levinson, S. C. (1996). Relativity in spatial conception and description. In J. J. Gumperz \& S. C. Levinson (Eds.), Retbinking linguistic relativity (pp. 177-202). Cambridge: Cambridge University Press.

Levinson, S. C., Kita, S., Haun, D. B. \& Rasch, B. H. (2002). Returning the tables: Language affects spatial reasoning. Cognition, 84(2), 155-188.

Levy, S., Freitas, A. \& Salovey, P. (2002). Construing action abstractly and blurring social distinctions: Implications for perceiving homogeneity among, but also empathizing with and helping, others. Journal of Personality and Social Psychology, $83,1224-1238$.

Liberman, N. \& Trope, Y. (1998). The role of feasibility and desirability considerations in near and distant future decisions: A test of temporal construal theory. Journal of Personality and Social Psychology, 75, 5-18.

Liberman, N. \& Trope, Y. (2008). The psychology of traversing the here and now. Science, 322, 1201-1205.

Liberman, N. \& Förster, J. (2009). Distancing from experienced self: How globalversus-local perception affects estimation of psychological distance. Journal of personality and social psychology, 97(2), 203.

Liberman, N. \& Trope, Y. (2014). Traversing psychological distance. Trends in cognitive sciences, 18(7), 364-369.

Liberman, N., Sagristano, M. \& Trope, Y. (2002). The effect of temporal distance on level of construal. Journal of Experimental Social Psychology, 38, 523-535.

Liberman, N., Trope, Y. \& Stephan, E. (2007). Psychological distance. In A. W. Kruglanski \& E. T. Higgins (Eds.), Social psychology: Handbook of basic principles (pp. 353-381). New York: Guilford Press.

Liberman, N., Trope, Y., Macrae, S. \& Sherman, S. (2007). The effect of level of construal on temporal distance. Journal of Experimental Social Psychology, 43, 143149.

Liviatan, I., Trope, Y. \& Liberman, N. (2008). The effect of similarity on mental construal. Journal of Experimental Social Psychology, 44, 1256-1269.

Lucy, J. (1992). Grammatical categories and cognition: A case study of the linguistic relativity bypothesis. Cambridge: Cambridge University Press.

Majid, A., Bowerman, M., Kita, S., Haun, D. B. \& Levinson, S. C. (2004). Can language restructure cognition? The case for space. Trends in cognitive sciences, 8(3), 108-114. 
McCrae, S. M., Liberman, N., Trope, Y. \& Sherman, S. J. (2008). Construal level and procrastination. Psychological Science, 19, 1308-1314.

Mikulincer, M., Kedem, P. \& Paz, D. (1990). Anxiety and categorization: 1. The structure and boundaries of mental categories. Personality and Individual Differences, 11, 805-814.

Miles, L. K., Tan, L., Noble, G. D., Lumsden, J. \& Macrae, C. N. (2011). Can a mind have two time lines? Exploring space-time mapping in Mandarin and English speakers. Psychonomic Bulletin \& Review, 18, 598-604.

Navon, D. (1977). Forest before trees: The precedence of global features in visual perception. Cognitive Psychology, 9, 353-383.

Papafragou, A., Massey, C. \& Gleitman, L. (2006). When English proposes what Greek presupposes: The cross-linguistic encoding of motion events. Cognition, 98(3), B75-B87.

Papafragou, A., Hulbert, J. \& Trueswell, J. (2008). Does language guide event perception? Evidence from eye movements. Cognition, 108(1), 155-184.

Park, H. I. \& Ziegler, N. (2014). Cognitive shift in the bilingual mind: Spatial concepts in Korean-English bilinguals. Bilingualism: Language and Cognition, 17(02), 410430. Doi: doi:10.1017/S1366728913000400

Penn, D. C., Holyoak, K. J. \& Povinelli, D. J. (2008). Darwin's mistake: Explaining the discontinuity between human and nonhuman minds. Behavioral and Brain Sciences, 31(02), 109-178.

Pulvermüller, F. (2003). The neuroscience of language: On brain circuits of words and serial order. Cambridge, UK: Cambridge University Press.

Roberson, D. (2005). Color categories are culturally diverse in cognition as well as in language. Cross-Cultural Research, 39, 56-71.

Stapel, D. A. \& Semin, G. R. (2007). The magic spell of language: Linguistic categories and their perceptual consequences. Journal of Personality and Social Psychology, 93, 23-33.

Stephan, E., Liberman, N. \& Trope, Y. (2010). Politeness and social distance: A construal level perspective. Journal of Personality and Social Psychology, 98, 268280.

Trope, Y. \& Liberman, N. (2003). Temporal construal. Psychological Review, 110, 403421. 
Trope, Y. \& Liberman, N. (2010). Construal-level theory of psychological distance. Psychological review, 117(2), 440.

VandenBos, G. R. (2015). APA Dictionary of Psychology. Washington. D.C.: American Psychological Association.

Wakslak, C. J. \& Trope, Y. (2009). The effect of construal-level on subjective probability estimates. Psychological Science, 20, 52-58.

Wakslak, C. J., Trope, Y., Liberman, N. \& Alony, R. (2006). Seeing the forest when entry is unlikely: Probability and the mental representation of events. Journal of Experimental Psychology: General, 135, 641-653.

Wolff, P. \& Holmes, K. J. (2011). Linguistic relativity. Wiley Interdisciplinary Reviews: Cognitive Science, 2(3), 253-265.

\section{NOTES}

${ }^{1}$ QPT score from 1 to 13.

${ }^{2}$ QPT score from 18 to 31.

${ }^{3}$ QPT scores from 42 to 60. 